Original Article

\title{
FINGERPRINT PATTERN CHARACTERISTICS OF INTELLECTUALIY DISABLED CHILDREN - AN ORIGINAL STUDY
}

\author{
Meril Ann Soman ${ }^{1}$, Ramakrishna Avadhani ${ }^{2}$, Rani Nallathamby ${ }^{3}$, Meera Jacob ${ }^{4}$, \\ Charly Chacko Joseph ${ }^{5}$
}

Post Graduates ${ }^{1,3,5}$, Professor \& HOD ${ }^{2}$, Assistant Professor ${ }^{4}$, Department of Anatomy, Yenepoya Medical College, M angalore, ${ }^{5}$ Department of Anaesthesia, M ahatma Gandhi Medical College and Research Institute, Pondicherry, India.

Correspondence :

Charly Chacko Joseph

Post Graduate, Department of Anaesthesia, M ahatma Gandhi Institute of M edical Science and Research Centre, Pondicherry 607 402, India.

E-mail : drcharlychackojoseph007@gmail.com

\begin{abstract}
:
Fingerprint patterns are unique patterns made by friction ridges and furrows present on the pads of finger tips. Uniqueness and persistence are the two underlying features of fingerprint patterns. Aim of this present study was to determine the differences in the incidence of fingerprint patterns in intellectually disabled children compared to normal healthy children. Intellectual disability is a generalized disorder appearing before adulthood and is characterized by limitations in both intellectual functioning and in adaptive behavior. The present study comprising of 120 students (60 intellectually disabled and 60 controls) was carried out in Pediatrics outpatient department, Yenepoya M edical College and Hospital, Mangalore. The incidence of the four fingerprint patterns (UInar loop, Radial loop, Whorls and Arches) were determined in both the groups. Ulnar loop pattern had the highest incidence in both the groups and the least incidence was shown by arch pattern. There exists difference in the frequency of the fingerprint patterns in males and females of both the groups. The study was conducted to observe for any difference in the incidence of fingerprint patterns between intellectually disabled and normal children.
\end{abstract}

Keywords: Fingerprint, Intellectually disabled, Loop, Dermatoglyphics

\section{Introduction:}

Fingerprint patterns are impressions made by the minute ridge formations or furrows present on the fingertips. The dermal ridges are formed during $3^{\text {rd }}$ month of intrauterine life. The fingerprint patterns are genetically determined and the pattern once formed doesn't alter with developmental or environmental changes. Human fingerprints are unique and they offer an infallible means of personal identification. ${ }^{(1),(2)}$

Intellectual disability, also known as mental retardation is characterized by below average intellectual functioning level and significant Access this article online Quick Response Code

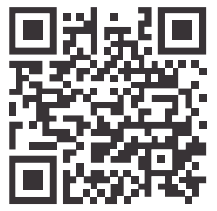
limitations in daily living skills. ${ }^{(3)}$ Symptoms may appear at birth or in early childhood. Common signs and symptoms include developmental delay, difficulties with problem solving skills and in learning social rules. M ostly, it persists throughout adulthood. The causes for intellectual disability include genetic factors, prenatal maternal infections, childhood illnesses, injuries and environmental factors such as malnutrition. ${ }^{(4)}$

Fingerprint patterns are of multifactorial polygenic inheritance. Many chromosomal disorders have characteristic dermatoglyphic patterns which may aid in the diagnosis of those disorders. In this study, the dermatoglyphic patterns of the intellectually disabled children were compared with the controls. An attempt has been made to study whether there exist any difference in the incidence of the fingerprint patterns in both the groups.

\section{Materials and Methods}

This prospective study was done among subjects who had visited the Pediatrics outpatient department of Yenepoya M edical College and Hospital. The study included a total of 
120 subjects (60 intellectually disabled and 60 controls) in the age group of 8-14 years. Each group consisted of 30 males and 30 females. The subjects were requested to wash their hands with soap and water and dry it using a clean hand towel. The ink pad used was of Faber Castell Company of size $110 \mathrm{~mm} * 69 \mathrm{~mm}$. A white sheet of paper was provided which had 10 different blocks for all fingers of both the hands. The subject was asked to press his/her fingertips on the stamp pad and thereafter to the white paper to transfer the fingerprint impression. Specific number was given to each digit. Right thumb was marked as 1 and number 10 was given to left little finger. Other details such as age and sex of each subject were noted. Subjects with any hand deformity or permanent scars on the fingertips were excluded from the study.

\section{Results:}

The study was carried out in 120 children of age group 8-14 years of which 60 subjects were intellectually disabled and 60 were controls. 30 males and 30 females were present in each group.

Table 1 : Distribution of fingerprint patterns in intellectually disabled and controls

\begin{tabular}{|l|c|c|c|c|}
\hline Fingerprint & \multicolumn{2}{|c|}{ Intellectually Disabled } & \multicolumn{2}{c|}{ Controls } \\
\hline Patterns & Number & $\%$ & Number & $\%$ \\
\hline ULNAR LOOP & 324 & $54 \%$ & 386 & $64.3 \%$ \\
\hline RADIAL LOOP & 47 & $7.8 \%$ & 20 & $3.4 \%$ \\
\hline WHORLS & 205 & $34.2 \%$ & 156 & $26 \%$ \\
\hline ARCHES & 24 & $4 \%$ & 38 & $6.3 \%$ \\
\hline TOTAL & $\mathbf{6 0 0}$ & $\mathbf{1 0 0} \%$ & $\mathbf{6 0 0}$ & $\mathbf{1 0 0} \%$ \\
\hline
\end{tabular}

Table-1 shows distribution of fingerprint patterns in intellectually disabled and controls. Ulnar loop pattern shows the highest incidence in both the groups followed by whorls. Arches show the least frequency in intellectually disabled and radial loop pattern is found to be the least among controls.

TABLE 2 : Distribution of fingerprint patterns according to gender in intellectually disabled and controls

\begin{tabular}{|l|c|c|c|c|c|c|c|c|}
\hline \multirow{2}{*}{$\begin{array}{l}\text { Fingerprint } \\
\text { Patterns }\end{array}$} & \multicolumn{3}{|c|}{ Intellectually Disabled } & \multicolumn{4}{c|}{ Control } \\
\cline { 2 - 10 } & \multicolumn{2}{|c|}{ Males } & \multicolumn{2}{c|}{ Females } & \multicolumn{2}{c|}{ Males } & \multicolumn{2}{c|}{ Females } \\
\cline { 2 - 9 } & Number & $\%$ & Number & $\%$ & Number & $\%$ & Number & $\%$ \\
\hline Ulnar loops & 162 & $54 \%$ & 162 & $54 \%$ & 184 & $61.3 \%$ & 202 & $67.4 \%$ \\
\hline Radial loops & 18 & $6 \%$ & 29 & $9.7 \%$ & 16 & $5.3 \%$ & 04 & $1.3 \%$ \\
\hline Whorls & 114 & $38 \%$ & 91 & $30.3 \%$ & 86 & $28.7 \%$ & 70 & $23.3 \%$ \\
\hline Arches & 06 & $2 \%$ & 18 & $06 \%$ & 14 & $4.7 \%$ & 24 & $08 \%$ \\
\hline Total & 300 & $100 \%$ & 300 & $100 \%$ & 300 & $100 \%$ & 300 & $100 \%$ \\
\hline
\end{tabular}

Table 2 shows the distribution of fingerprint patterns according to gender in intellectually disabled and control groups. Ulnar loop shows the highest frequency in males and females of both the groups followed by whorls. Arches show the least frequency in males of both the groups and also in females of intellectually disabled group.

TABLE 3 : Side wise distribution of fingerprint patterns in males and females of intellectually disabled subjects and controls

\begin{tabular}{|c|c|c|c|c|c|c|c|c|c|c|}
\hline & \multirow[t]{2}{*}{ SEX } & \multirow[t]{2}{*}{ SIDE } & \multicolumn{2}{|c|}{ ULNAR LOOPS } & \multicolumn{2}{|c|}{ WHORLS } & \multicolumn{2}{|c|}{ ARCHES } & \multicolumn{2}{|c|}{ RADIAL LOOPS } \\
\hline & & & Number & $\%$ & Number & $\%$ & Number & $\%$ & Number & $\%$ \\
\hline \multirow{4}{*}{$\begin{array}{l}\text { Intellectually } \\
\text { disabled }\end{array}$} & \multirow[t]{2}{*}{ MALE } & RIGHT & 84 & $56 \%$ & 53 & $35.3 \%$ & 03 & $02 \%$ & 10 & $6.7 \%$ \\
\hline & & LEFT & 78 & $52 \%$ & 61 & $40.7 \%$ & 03 & $02 \%$ & 08 & $5.3 \%$ \\
\hline & \multirow[t]{2}{*}{ FEM ALE } & RIGHT & 85 & $56.7 \%$ & 47 & $31.3 \%$ & 05 & $3.3 \%$ & 13 & $8.7 \%$ \\
\hline & & LEFT & 77 & $51.3 \%$ & 44 & $29.3 \%$ & 13 & $8.7 \%$ & 16 & $10.7 \%$ \\
\hline \multirow[t]{4}{*}{ Controls } & \multirow[t]{2}{*}{ MALE } & RIGHT & 91 & $60.7 \%$ & 47 & $31.3 \%$ & 08 & $5.3 \%$ & 04 & $2.7 \%$ \\
\hline & & LEFT & 93 & $62 \%$ & 39 & $26 \%$ & 06 & $04 \%$ & 12 & $08 \%$ \\
\hline & \multirow[t]{2}{*}{ FEMALE } & RIGHT & 102 & $68 \%$ & 33 & $22 \%$ & 13 & $8.7 \%$ & 02 & $1.3 \%$ \\
\hline & & LEFT & 100 & $66.7 \%$ & 37 & $24.7 \%$ & 11 & $7.3 \%$ & 02 & $1.3 \%$ \\
\hline
\end{tabular}

Table 3 shows sidewise distribution of fingerprint patterns in males and females of intellectually disabled subjects and controls. Ulnar loops followed by whorls showed the highest predominance on both sides in males and females of both the groups. 


\section{Discussion :}

Dermatoglyphics is the scientific study of fingerprints. The term 'dermatoglyphics' was coined from the Greek word 'derma' which means 'skin' and the term 'glyphic' which means carving'. Fingerprint patterns are easily deposited on suitable surfaces by sweat secretions from the eccrine glands present in the friction ridges of finger tips. ${ }^{(5),(6)}$ Less variation is seen in fingerprint patterns among subjects with genetic syndromes than between control subjects. Dermatoglyphics is an emerging field which acts as a non invasive and early predictor of mental retardation in children. The study of dermatoglyphics is a simple, yet complicated tool to diagnose the chromosomal abnormalities. ${ }^{(7)}$

In the present study, the incidence of fingerprint patterns in intellectually disabled was compared with control subjects. The study was done sex wise and side wise. The four fingerprint patterns taken into consideration were ulnar loop, radial loop, whorls and arches. UInar loop had the highest incidence in both the groups followed by whorls. Arch pattern was seen the least in intellectually disabled whereas radial loops had the least frequency among controls. In sex wise distribution of fingerprint patterns among intellectually disabled, ulnar loop pattern showed equal frequency in both the sexes, whorls were seen to be more in males compared to females whereas radial loops and arches were seen more in females. In

\section{References:}

1. Dr. Rastogi P, Ms. Pillai K.R. A study of Fingerprints in Relation to Gender and Blood Group. J Indian Acad Forensic M ed. 2010; 32(1): 1114.

2. Bhavana D, Ruchi J, Prakash T, L.K.J. Study of Fingerprint Patterns In Relationship with Blood Group and Gender- a Stastical Review. Res.J. Forensic Sci. 2013 M arch; 1(1): 15-17.

3. Sharma M K, Jhawar P, Sharma H, Sharma S, Kalavatia I. Dermatoglyphics an attempt to predict downs syndrome. Int J Biol Med Res. 2012; 3(2):1631-1635

4. Alter $M$, Bruhel $H$. Dermatoglyphics in idiopathic mental retardation. American Journal of Diseases in children. 1967; 113: 702-706.

5. http://en.wikipedia.org/wiki/Fingerprint

6. Pillay V.V. 2009. Textbook of Forensic M edicine and Toxicology. 15th ed. Hyderabad. Paras M edical Publishers. 53-94.

7. Clare Davison. Dermatoglyphic in patients with idiopathic severe subnormality and Genetic studies in mental subnormality. British Journal of Psychiatry special publication. 1973; 8: 21-24.

8. Bhagwat V B, Meshram M M. Study of Palmar Dermatoglyphics in M entally Retarded Children. IOSR-JDM S. 2013; 8(1):23-27 sidewise distribution of patterns among mentally retarded, right side showed higher frequency of ulnar loops among males and females.

A study was conducted in 2013 by Dr. Bhagwat V B on palmar dermatoglyphics in mentally retarded children which also showed the predominance of ulnar loop pattern. According to Dr. Bhagwat V B, among mentally retarded children, the percentage of ulnar loop was higher in males compared to females. ${ }^{(8)}$ Whereas in the present study, both males and females shared equal frequencies of ulnar loops, whorls were seen more in males and radial loops and arches were seen more in females.

\section{Conclusion:}

Dermatoglyphics, as a non invasive approach can definitely aid in the early detection of mental retardation in children. Since the dermatoglyphic patterns are established by birth, it can be considered as a diagnostic tool in identifying various genetic abnormalities in children. Therefore dermatoglyphics can be considered as an inexpensive and noninvasive screening method in certain genetic disorders.

\section{Acknowledgement:}

Authors sincerely thank all the participants of this study and also Dr. Bhagya B Sharma, Lecturer, Department of Anatomy, Yenepoya Medical College, Mangalore, for her kind co-operation and help during this study. 